\title{
Laparoscopic varicocelectomy initial experience at Al_Azhar Hospital (Demietta)
}

\author{
Ali Mohamed Farag, Ahmed Youssef Abo-Elsaad, Yasser Ali Ahmed, Ahmed Saber Mohamed \\ Azzam
}

Department of Urology, Faculty of Medicine, Al-Azhar University

Corresponding author: Ahmed Saber Mohamed Azzam, Mobile: 01023265742, E-mail: drazzam19882014@gmail.com

\begin{abstract}
Background: Varicocele is a collection of dilated veins in the pampiniform plexus that drain the testicle and may contribute to male infertility. A variety of surgical \& non-surgical approaches have been advocated for varicocele treatment.

Objective: Evaluate laparoscopic varicocelectomy with regard to intra and post-operative parameters. Patients and Methods: At Departments of urology of Al_azhar University Hospitals (Damietta). Prospective randomized study was performed about laparoscopic varicocelectomy during the period from June 2016 to December 2017 after obtaining informed consent. The group included patients with clinically palpable varicocele confirmed by U/S complaining of infertility (primary, secondary) or chronic testicular pain.

Results: The range operative bilateral Laparoscopic Varicocelectomy time was 60-90 minutes. There were no intra operative complications in the study group. The average hospital stay was 24-36 hours. Post-operative analgesics (2-3) doses, daily activities initiation usually started after 4-5days. Hydrocele formation was seen in $(11.1 \%)$ patients recurrence was seen in (5.6\%) patient. None of the patient has developed an atrophic testis as a result of the laparoscopic procedure. Patients had improvement of the seminal fluid parameters during follow up period and pregnancy rate was $(25 \%)$.
\end{abstract}

CONCLUSION: Laparoscopic varicocele ligation is a simple and safe technique causing minimal morbidity and enabling rapid return to normal activity.

Keywords: varicocele, laparoscopy, infertility.

\section{INTRODUCTION:}

Varicocele is one of the most common causes of male infertility ${ }^{(1)}$. Varicocele is found in $25 \%$ of men with abnormal semen parameters, compared with $12 \%$ of men with normal semen parameters, suggesting that it is associated with impaired testicular function and male infertility. Nevertheless, only $20 \%$ of men suffer from infertility problems among adults with documented varicocele ${ }^{(2)}$.

The causes of varicocele largely remain unknown, as does the pathophysiology of varicocele $^{(3)}$.

Typically, men with varicocele are asymptomatic; Physical examination is the mainstay of varicocele diagnosis. Both adult and adolescent varicocele are graded as follows: grade I, palpable impulse in the spermatic cord veins during Valsalva maneuver without enlargement of the veins at rest; grade II, palpable engorged veins with the patients standing without Valsalva maneuver, but not visible; grade III, veins easily visible through the scrotal skin while the patient is standing ${ }^{(4)}$.

The optimal technique for varicocelectomy is still a matter of controversy.
Techniques include open surgical ligation of the spermatic vein, retrograde or anterograde sclerotherapy, microsurgery, and laparoscopy. Each technique has its own advantages and disadvantages ${ }^{(5)}$.

Surgery is currently the most popular treatment of varicocele patients with sign of abnormal semen, testicular hypertrophy or pain. The recurrence rates following varicocele repair range from $5 \%$ to $20 \%$ depending upon the technique used. The main causes of high recurrence varicocelectomy are developed collateral within the interrupted venous drainage system and persistence or progression of uninterrupted pathological venous drainage routes ${ }^{(6)}$.

Currently, the best approach for the treatment of adolescent varicocele has not been established. There are three options for a surgical varicocele repair: retroperitoneal (Palomo), inguinal and sub inguinal approaches. In the last 2 decades, varicocelectomy has been performed successfully via laparoscopy ${ }^{(7)}$.

Laparoscopic varicocelectomy was first introduced as an efficient treatment for male infertility in 1992. Aaberg et al. reported 
the first Laparoscopic varicocelectomy in 1991

${ }^{(8)}$. Different ligation technique can be used for ligation varicose veins, such as ligation by electro surgical devices, surgical silk and titanium clips ${ }^{(9)}$.

Although there are many literature examining the possible effect of varicocelectomy on classic semen parameters and recurrence rate, few published article have examined the effect of conventional laparoscopic varicocelectomy on sperm DNA integrity, which provide an ideal access to treat varicocele due to clear visualization of most of the involved venous system (internal spermatic vein, external spermatic vein, deferential veins) which still have the same problem of recurrence (10).

\section{AIM OF THE WORK}

In the present study, we aim to evaluate laparoscopic varicocelectomy with regard to parameters, such as semen parameter, pregnancy rate, operative time, hospital stay, intraoperative and postoperative complications.

\section{Patients and Methods}

At Department of Urology of Al_Azhar University Hospital (Damietta). prospective randomized study was performed about laparoscopic varicocelectomy during the period from June 2016 to December 2017 .The studied group included patients with clinically palpable varicocele confirmed by U/S complaining of infertility (primary, secondary) or varicocele induced scrotal pain.

Preoperative: History, clinical examination, Lab investigation: two semen analysis, CBC, coagulation profile, serum creatinine, R.B.S, liver function test, and Imaging: color Doppler ultrasonography.

Operative details: Laparoscopic surgery by the three-port approach proceeded with patient placed in a supine low lithotomy position under general anesthesia. Veress needle was introduced through the umbilicus with $\mathrm{CO}_{2}$ gas inflation for creation of a carbon dioxide pneumoperitoneum of $14 \mathrm{mmHg}$ pressure. A $20-\mathrm{mL}$ needle syringe containing saline was inserted to test that the needle was in the intraperitoneum before passing $\mathrm{CO}_{2}$ through the Veress needle. The saline should flow freely and no blood or fecal contents should be withdrawn,The needle was then withdrawn and the abdomen was ready for laparoscopy. A 5$\mathrm{mm}$ trocar was then introduced via transverse midline immediate sub umbilical incision, followed by inserting telescope through, by using video camera clipped onto the eyepiece, allowing a clear view of the abdominal cavity and pelvis. Then the patient was placed in the modified Trendelenburg position. Two 5-mm trocars were then introduced through the lateral aspect of the abdomen on distance two-third from the umbilicus to the anterior superior iliac spine. The testicular vascular bundle of each side was identified. The right bundle was operated on first. The vascular bundle was traced down vertically to its entry into the internal ring and the vas deferens was also noted to emerge from the ring medially and running into the pelvis. These landmarks were always observed before proceeding further. The parietal peritoneum over the bundle was lifted up, a 1-cm transverse incision was made and the connective tissue between the vessels was separated by teasing it apart.

First the testicular artery was identified with varying degrees of prominence of pulsation. The testicular veins were exposed and clipped in 2 places with very small titanium clips and cut in between to prevent recanalization. The operation proceeded with the left side in the same manner as with the right side. At the conclusion of the operation, $\mathrm{CO}_{2}$ was expelled completely from the abdomen and the abdominal incisions were sutured.

Postoperative: History and clinical examination. Semen analysis at 3, 6, and 12 months postoperatively. Color Doppler ultrasonography at 6 and 12 months.

\section{RESULTS}

Scrotal edema occurred in one patient and subsides within few days with management by conservative treatment (non-steroidal antiinflammatory drugs and scrotal elevator). Wound infection was noticed in one patient at the site of trocar insertion and it was managed conservatively. No epididmo-orchitis, hematoma or urine retention developed after the operation.

Table (1): Shows the number and percentage of early postoperative complication.

\begin{tabular}{|l|l|l|}
\hline Early postoperative complication & $\mathrm{N}(\%)$ \\
\hline \multirow{2}{*}{ Edema } & Yes & $1(5.6 \%)$ \\
\cline { 2 - 3 } & No & $17(94.4 \%)$ \\
\hline Infection & Yes & $1(5.6 \%)$ \\
\hline
\end{tabular}




\begin{tabular}{|l|l|l|}
\hline \multirow{2}{*}{ Orchitis } & No & $17(94.4 \%)$ \\
\hline \multirow{2}{*}{ Hematoma } & Yes & $0(0 \%)$ \\
\cline { 2 - 3 } & No & $18(100 \%)$ \\
\hline & Yes & $0(0 \%)$ \\
\cline { 2 - 3 } & No & $18(100 \%)$ \\
\hline
\end{tabular}

Preoperative semen quality was compared with that after laparoscopic varicocelectomy at 3 months, 6 months, and at 12 months postoperatively. The semen mean volume increased from $2.91 \pm 1.51 \mathrm{~mL}$ preoperative to $3.08 \pm 1.22 \mathrm{~mL}, 3.08 \pm 1.22 \mathrm{~mL}$, and $3.25 \pm 1.3 \mathrm{ml}$ postoperative at 3,6 , and 12 months respectively. The median density also varied from 26.1 to $31.4 \mathrm{~m} / \mathrm{mL}, 36 \mathrm{~m} / \mathrm{mL}$ and 37.9 $\mathrm{m} / \mathrm{mL}$ postoperative at 3,6 , and 12 months respectively. The mean motility improved from $32.5 \pm 6.02$ $\%$ to $39.3 \pm 7.4 \%, 42.6 \pm 8.01 \%$ and $483 \pm 8.8 \%$ postoperative at 3,6 , and 12 months respectively. The median morphology also varied from $32.5 \%$ to $33.5 \%, 34.5 \%$ and $35.5 \%$ postoperative at 3,6 , and 12 months respectively. The mean semen vitality varied from $57.7 \pm 15.1 \%$ to $58.2 \pm 13.8 \%, 59.6 \pm 13.3 \%$ and $62.5 \pm 15.3 \%$ postoperative at 3,6 , and 12 months respectively.

Table (2): Evaluation of patient semen parameters preoperative and follow up at 3, 6, and 12 months postoperative.

\begin{tabular}{|c|c|c|c|c|c|}
\hline & \multirow{2}{*}{ Preoperative } & \multicolumn{3}{|l|}{ Follow up } & \multirow[b]{2}{*}{ p. } \\
\hline & & $3 \mathrm{~m}$ & $6 \mathrm{~m}$ & $12 \mathrm{~m}$ & \\
\hline Volume & $2.91 \pm 1.51$ & $3.08 \pm 1.22$ & $3.08 \pm 1.22$ & $3.25 \pm 1.3$ & 0.899 \\
\hline Count & $61.1(11.2-198)$ & $78.2(27.6-180)$ & $110(30.2-267)$ & 113.9 (30.4-231) & 0.086 \\
\hline Density & $26.1(3.2-49.4)$ & $31.4(12.3-49.7)$ & $36(14.1-54.4)$ & $37.9(18-53.4)$ & 0.056 \\
\hline Motility & $32.5 \pm 6.02$ & $39.3 \pm 7.4$ & $42.6 \pm 8.01$ & $48.3 \pm 8.8$ & 0.0001 \\
\hline Morphology & $32.5(5-70)$ & $33.5(5-68)$ & $34.5(6-70)$ & $35.5(6-70)$ & 0.997 \\
\hline Vitality & $57.7 \pm 15.1$ & $58.2 \pm 13.8$ & $59.6 \pm 13.3$ & $62.5 \pm 15.3$ & 0.755 \\
\hline
\end{tabular}

4 partners of patients who obtained laparoscopic varicocelectomy achieved pregnancy with a pregnancy rate of $25 \%$ of patient with infertility complain.

Table (3): Pregnancy outcome.

\begin{tabular}{|l|l|l|}
\hline \multicolumn{2}{|l|}{ Surgical outcome } & N (\%) \\
\hline \multirow{2}{*}{ Pregnancy } & Yes & $4(25 \%)$ \\
\cline { 2 - 3 } & No & $12(75 \%)$ \\
\hline
\end{tabular}

Postoperative complications were detected as fellow. Hydrocele developed in $2(11.1 \%)$ of patients, one patient was mild bilateral hydrocele and the other required hydrocelectomy. Recurrence of varicocele occurred in 1 patients with rate of $(5.6 \%)$.

Table (4): Late postoperative complications.

\begin{tabular}{|l|l|l|}
\hline \multicolumn{2}{|l|}{ Surgical outcome } & $\mathbf{N}(\mathbf{\%})$ \\
\hline \multirow{2}{*}{ Hydrocele } & Yes & $2(11.1 \%)$ \\
\cline { 2 - 3 } & No & $16(88.9 \%)$ \\
\hline \multirow{2}{*}{ Recurrence } & Yes & $1(5.6 \%)$ \\
\cline { 2 - 3 } & No & $17(94.4 \%)$ \\
\hline
\end{tabular}

No testicular atrophy developed after laparoscopic varicocelectomy as confirmed by Doppler ultrasonography at 6,12 months postoperative. The testicular volume (mean $\pm \mathrm{SD})$ was $18.8 \pm 2.11 \mathrm{~mL}$ preoperative and $19.02+2.1 \mathrm{~mL}, 19.04+06 \mathrm{~mL}$ postoperative at 6 , and 12 months respectively. These results support the laparoscopic technique for the treatment of varicoceles.

Table (5): Testicular volume pre and postoperative show insignificant difference in testicular volume with follow up at $6 \mathrm{~m}, 12 \mathrm{month}$.

\begin{tabular}{|l|l|l|}
\hline Testicular volume & Mean \pm SD & P. \\
\hline Preoperative & $18.8 \pm 2.11$ & \multirow{2}{*}{0.497} \\
\hline 6months & $19.02 \pm 2.1$ & \\
\hline 12months & $19.04 \pm 2.06$ & \\
\hline
\end{tabular}

\section{DISCUSSION}

The main goal of varicocelectomy is to preserve testicular function and initiate pregnancy in infertile couples ${ }^{(11)}$.
A variety of surgical approaches have been advocated for varicocelectomy, they include minimally invasive procedures, such as 
laparoscopic varicocele ligation, trans venous percutaneous embolization and traditional open surgical approach (retro peritoneal, inguinal and sub inguinal ${ }^{(12)}$.

The two most common complications in any type of treatment are hydrocele formation and varicocele persistence. Different approaches exist to be used for elimination of varicocele but the ideal technical option in term of low recurrence rate and hydrocele formation is not yet decided ${ }^{(13)}$.

Recent meta-analysis and literature reviews showed that outcomes are comparable between laparoscopic varicocelectomy and other surgical procedure ${ }^{(14)}$.

The technique of laparoscopic varicocelectomy has gained wide acceptance since its introduction by Winfield and his colleagues in 1991 reports have suggested that laparoscopic approach not only carried lesser morbidity, less post-operative pain, early return to routine work, but also had the same success rate as open procedures ${ }^{(15)}$.

Recently, the laparoscopic approach to varicocele ligation has gained favor for bilateral varicoceles. The built-in magnification of the laparoscope facilitates identification of the spermatic veins and artery, potentially reducing the risk of recurrence of the varicocele and of ischemic damage to the testis. Magnification also allows the surgeon to preserve lymphatics and the genital branches of the genitofemoral nerve that runs along the spermatic vessels, which may reduce lymphocele formation and postoperative pain. laparoscopic management of varicoceles in adults may reflect the excellent visibility of the posterior abdominal wall achieved using the laparoscope, which allows a thorough search of sites known to be responsible for recurrent varicoceles, namely renal, vas associated, pelvic, and retro pubic cross-over veins ${ }^{(16)}$.

The clear magnified surgical field provided by the laparoscopy allows more accurate identification of vessels with subsequent minimization of recurrence, hydrocele formation and testicular atrophy, therefore, the use of an operating laparoscope providing magnification allows a better preservation of the testicular arteries and lymphatic vessels during approach ${ }^{(17)}$.

The average operating time for laparoscopic varicocelectomy after the training period has been completed was 44 minutes in series by Jiménez $1999{ }^{(18)}$. The operating time required for laparoscopic surgery is significantly longer than that for the open surgery ${ }^{(19)}$.

Majority of patients perceived minimal pain and had mild grade of pain as per VAS scale, analgesic requirement of patients was 2 to 3 doses of analgesics in the postoperative period.

It is a same-day surgery procedure, resulting in rapid recovery, early return to normal activity which may be attributed to decreased postoperative pain in contrast to open approaches, the high open retroperitoneal ligation of spermatic vein is associated with significant postoperative discomfort ${ }^{(20)}$.

In our study an average hospital time of 24_36 hours. In our study post-operative hospital time was comparable to other available studies in literature and reported that the postoperative hospital stay was 52 hours and 48.4 hours in open and laparoscopic varicocelectomy group, respectively ${ }^{(21)}$.

No major intraoperative complications occurred, no vascular or intestinal complications occurred while the operations, no blood transfusion was required, no conversion from laparoscopic to open varicocelectomy was done, no morbidity and mortality were encountered in the study.

In our study we performed the artery and lymphatic sparing approach and encountered 2 cases $(11.1 \%)$ of hydrocele formation during one year follow up after surgery, with little likelihood of recurrence of the pathology 1 case (5.6\%).

Mass ligation can be a safe approach with significantly lower recurrence and higher successful rates. On the other hand, this technique is associated with more postoperative discomfort and hydrocele formation. The risk of hydrocele formation after mass ligation of spermatic vessels ranges from $3 \%$ to 25 , as the laparoscopic approach may facilitate the identification of lymphatics; it is believed that sparing the lymphatics during the procedure may reduce the incidence of postoperative hydrocele ${ }^{(22-25)}$.

Misseri and colleagues observed very good outcomes after lymphatic sparing varicocelectomy. They compared postoperative hydrocele formation of the two techniques and reported a significantly higher 
rate of hydrocele formation after mass ligation (26). Kocvara and colleagues reported 17.9\% hydrocele formation with conventional laparoscopic varicocelectomy and $1.9 \%$ after lymphatic vessel preservation ${ }^{(17)}$.

Recurrence in our study was which is concurrent with the available literature, recurrence was observed in one patient $(5.6 \%)$ during follow-up period. Shamsa et al. reported recurrence in $2(6.7 \%)$ patients of laparoscopic group but it was not observed in patients who underwent open varicocelectomy (27). Podkamenev et al. reported relapse rate of $1.84 \%$ in laparoscopic group and $1.36 \%$ in open varicocelectomy group ${ }^{(28)}$.

Other surgeons have reported laparoscopic technique using the single incision laparoscopic surgery (SIL-V) or laparoendoscopic single site surgery with data suggests that single incision laparoscopic surgery is as safe and effective as conventional transperitoneal varicocelectomy (CTL-V). Friedersodroff et al. reported retrospective study included 20 patients with left-sided varicocele subjected to SIL-V compared to 79 patients subjected to CTL-V with Similar findings ${ }^{(29)}$.

In the follow up period of one year no complications such as incisional hernia, genitofemoral nerve damage or testicular atrophy were noticed.

Patients in our study, with the advantage of one year follow up for most patients showed a significant improvement in sperm parameters after laparoscopic varicocelectomy and resolution of testicular pain postoperative.

The improvement in quality of semen was analyzed and compared with the pre-operative semen analysis. Pre-operative semen analysis was done prior to surgery and then postoperative semen analysis was done 3, 6, and 12 months after varicocelectomy.

Also, the pregnancy rate at 1 year was not significantly different and was 25 in our study. Similar results are supported by various relevant studies ${ }^{(30)}$.

The important of the surgery is the degree of magnification obtained through the video laparoscopy, enabling a complete and thorough ligation of the testicular veins, without risk of injury to the testicular artery. It also enables bilateral ligation of the testicular veins in bilateral varicocele patient.

The technique requires skills and experience, In our present initial experience study titanium clips was used which facilitate veins ligation Some surgeons reported using laparoscopic technique with other ligation procedure, Standard bipolar diathermy technology may have some disadvantages in sticking and thermal spread ${ }^{(31)}$. Simforoosh and colleagues compared laparoscopic varicocelectomy using bipolar cautery to open high ligation approach for 100 men who were randomly allocated into two groups ${ }^{(32)}$. They observed that using bipolar cautery is a safe technique and can reduce costs compared to endoclips. Méndez-Gallart and colleagues used LigaSure technology to ligate spermatic veins for 63 men. They reported that using this system allows the surgeon to improve coagulation with minimal thermal spread to the surrounding tissues. Still, the initial cost and learning curve may be its disadvantage ${ }^{(33)}$.

On follow up the patients included in the study in the clinics, it was observed that patients with laparoscopic varicocelectomy were satisfied with their treatment.

Laparoscopic approach carries lesser postoperative morbidity; less post-operative pain with early return to work and in case of bilateral varicocele opposite side is dealt through the same ports. Therefore if facilities are available for this procedure and once perfection occurs in this minimally invasive technique, this is the procedure that gives lot of satisfaction to the patients as well as the operating surgeon.

\section{CONCLUSION}

Laparoscopic varicocele ligation is a simple and safe technique causing minimal morbidity and enabling rapid return to normal activity.

\section{REFERENCES}

1. Hassan JM, Adams MC, Pope JC et al. (2006): Hydrocele formation following laparoscopic varicocelectomy. J Urol., 175:1076-9.

2. Robinson SP, Hampton LJ, Koo HP (2010): Treatment strategy for the adolescent varicocele. Urol Clin North Am., 37: 269-78.

3. Garolla A, Torino M, Miola $P$ et al. (2015): Twenty-four-hour monitoring of scrotal temperature in obese men and men with a varicocele as a mirror of spermatogenic function. Hum Reprod., 30: 1006-13.

4. Al-Kandari AM, Shabaan H, Ibrahim HM et al. (2007): Comparison of outcomes of different varicocelectomy techniques: 
open inguinal, laparoscopic, and sub inguinal microscopic varicocelectomy: a randomized clinical trial. Urology, 69: 41720.

5. May M, Johannsen M, Beutner S et al. (2006): Laparoscopic surgery versus antegrade scrotal sclerotherapy: retrospective comparison of two different approaches of varicocele treatment. Eur Urol., 49:384-387.

6. Goldstein $M$ and Tanrikut $C$ (2006): Microsurgical management of male infertility. Nat Clin Pract Urol., 3: 381-91.

7. Dudai M, Sayfan J, Mesholam J, Sperber Y (1995): Laparoscopic simultaneous ligation of internal and external spermatic veins for varicocele. J Urol., 153:704-705.

8. Aaberg RA, Vancaillie TG, Schuessler WW (1991): Laparoscopic varicocele ligation: a new technique. Fertil Steril., 56:776-77715.

9. Glassberg KI, Poon SA, Gjertson CK et al. (2008): Laparoscopic lymphatic sparing varicocelectomy in adolescents. J Urol., 180: 326-30.

10. Will MA, Swain J, Fode M et al. (2011): The great debate: varicocele treatment and impact on fertility. Fertil Steril., 95: 841852.

11. Agarwal A, Deepinder F, Cocuzza $\mathrm{M}$ et al. (2007): Efficacy of varicocelectomy in improving semen parameters: new metaanalytical approach. Urology; 70: 532-8.

12. Mazzoni G, Fiocca G, Minucci $S$ et al. (1999): Varicocele: A multidisciplinary approach in children and adolescents. J Urol., 162:1755.

13. Baazeem A, Belzile E, Ciampi A et al. (2011): Varicocele and male factor infertility treatment: a new meta-analysis and review of the role of varicocele repair. Eur Urol; 60: 796-808.

14. Borruto $F$, Impellizzeri $P$, Pantonuccio et al. (2010): Laparoscopic versus open varicocelectomy in children and adolscents:review of the recent literature and meta_analysis, Jpediater.Surg.,45:2364-2469.

15. El-labban G (2011) : Results of varicocele surgery: A comparison of laparoscopic and conventional open high ligation. Egyptian Journal of Surgery, 3:1.
16. Franco I (2004): Laparoscopic varicocelectomy in the adolescent male. Curr Urol Rep., 5:132-6.

17. Kocvara R, Dvoracek J, Sedlacek J, Dite Z, Novak K (2005): Lymphatic sparing laparoscopic varicocelectomy: amicrosurgical repair. J Urol., 173: 17514.

18. Jiménez Garrido A, García de la Torre MV, Sánchez de Badajoz E (1999): A decade laparoscopic varicocelectomy: Cost and learning stages. Arch Esp Urol., 52(3): 245-248.

19. Ogura K, Matsuda T, Terachi T, Horii Y, Takeuchi H et al. (1994): Laparoscopic varicocelectomy: invasiveness and effectiveness compared with conventional open retroperitoneal high ligation. Int $\mathbf{J}$ Urol., 1(1): 62-66.

20. Palomo A (1949): Radical cure of varicocele by a new technique; preliminary report. J Urol., 61: 604-7.

21. Osman T, El-shourbay, Moustafa H, Maged W (2004): Laparoscopic versus open retroperitoneal bilateral varix ligation for obese patients presenting with primary sub-fertility: a randamized comperative study. African J of Urology, 10(1): 50-57.

22. Nyirady $P$, Kiss A, Pirot $L$ et al.(2002): Evaluation of 100 laparoscopic varicocele operations with preservation of testicular artery and ligation of collateral vein in children and adolescents. Eur Urol., 42:594-7.

23. Marte A, Sabatino MD, Borrelli $M$ et al.(2007): LigaSure vessel sealing system in laparoscopic Palomo varicocele ligation in children and adolescents. $\mathbf{J}$ Laparoendosc Adv Surg Tech A., 17:2725.

24. Esposito C, Monguzzi GL, GonzalezSabin MA et al.(2000): Laparoscopic treatment of pediatric varicocele: a multicenter study of the italian society of video surgery in infancy. J Urol., 163:19446.

25. Barry J, Nady M, Ragab G, El-Khalaf B, Abdallah A, Imich A(2012): Five $\mathrm{mm}$ laparoscopic varicocelectomy versus conventional varicocele ligation in young men with symptomatic varicocele: A randomized clinical study. African Journal of Urology, 18:12-5.

26. Misseri R, Gershbein AB, Horowitz $M$, Glassberg KI (2001): The adolescent 
varicocele. II: the incidence ofhydrocele and delayed recurrent varicocele aftervaricocelectomy in a long-term follow-up. BJU Int., 87:494-8.

27. Shamsa A, Mohammadi L, Abolbashri M, Shakeri MT, Shamsa S (2009): Comparison of open and laparoscopic varicocelectomies in terms of operative time, sperm parameters, and complications. Urol J., 6(3): 170- 175.

28. Podkamenev VV, Stalmakhovich VN, Urkov PS, Solovjev AA, Iljin VP (2002): Laparoscopic surgery for pediatric varicoceles: Randomized controlled trial. J Pediatr Surg., 37:727-9.

29. Freidersdorff F, Aghdassi S, Werthenmann $P$ et al. (2013): Laparoendoscopic single-site varicocelectomy with reusable components: comparison with conventional laparoscopic technique, Surg. Endosc.,27:3646-3652.

30. Bebars GA, Zaki A, Dawood AR, ElGohary MA (2000): Laparoscopic versus open high ligation of the testicular veins for the treatment of varicocele. JSLS., 4(3): 209-213.

31. Guerrieri M, Crosta F, De Sanctis A, Baldarelli M, Lezoche G, Campagnacci $\mathbf{R}(\mathbf{2 0 0 8})$ : Use of the electrothermal bipolar vessel system (EBVS) in laparoscopic adrenalectomy: a prospective study. Surg Endosc.., 22:141-5.

32. Simforoosh N, Ziaee SA, Behjati S, Beygi FM, Arianpoor A, Abdi H.(2007) :Laparoscopic management of varicocele using bipolar cautery versus open high ligation technique: a randomized, clinical trial. J Laparoendosc Adv Surg Tech A., 17:743-7.

33. Mendez-Gallart R, Bautista-Casasnovas A, Estevez-Martinez E, RodriguezBarca P (2011): Bipolarelectrothermal vessel sealing system and 5-mm 2expandable trocar approach in pediatric laparoscopic varicocelectomy: a successful time-effective technical refinement. Surg Laparosc Endosc Percutan Tech.; 21 :e2569. 